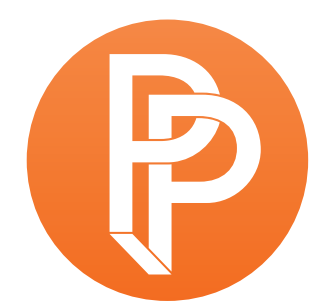

PERFORMANCE

PHILOSOPHY

\title{
BEUYS' CHAIR AND THE VIOLENCE OF THE OTHER: TOWARD A THEORY OF AESTH-ETHICS
}

\section{DROR PIMENTEL BEZALEL ACADEMY OF ART \& DESIGN JERUSALEM}

It would seem that no other artist has succeeded in harnessing his art to social and political engagement better than Joseph Beuys. This mainly holds true for Beuys' performance art (Aktion) of the 1960 s and 70 s that contributed greatly to the institutionalization of performance as a legitimate form of artistic expression. Beuys was not the first artist to practice performance: he was preceded by artists from the beginning of the $20^{\text {th }}$ century such as Hugo Ball, Filippo Marinetti, and Tristan Tzara. However, while these artists viewed performance as an experimental form of art that addressed a limited and elitist audience and generated enigmatic meaning, Beuys turned performance into a form of art that addressed a much wider audience and generated a much more accessible and communicative meaning.

Beuys' performance art is also distinguished by its engagement with pedagogy and politics. As shown by Cornelia Lauf, Beuys does not differentiate between his teaching and his artistic work, often mixing them together in various ways. For example, he includes relics of his teaching practice, such as a drawing board, in his performances (Lauf 1992, 16). Similarly, as illustrated by Caroline Tisdall, Beuys does not differentiate between an act of performance and a political act. His performances practice the politics of disseminated power, and in this way, they continually challenge the common notion of democracy, while transporting it to radical democracy (Tisdall 1998).

As Beuys' performance art-which resists fixed definition by constantly oscillating between artistic, pedagogic, and political action-has already been widely addressed in academic literature, this article does not attempt to contribute to this discussion. Rather, it aims to reflect on Beuys' art 
from another perspective, one that is phenomenological rather than socio-political. To this aim, the article will forgo reflection on Beuys' performance art and will instead focus on his sculpture, mainly the sculpture Fat Chair, dated 1964, which has a performativity of its own.

This performativity - so the article wishes to argue-manifests brilliantly the tension between the violence of culture and the violence of the primordial Other which culture negates via the processes of limitation and economy, thought in their broad sense. Thus it could be argued that Beuys' artistic practice gives a visual manifestation of the aporia of culture and nature in a way that is other than that of the theoretical academic discourse. By so doing, it could be further argued that Beuys' art subverts the traditional categorical distinction separating art from philosophy. Just as Nietzsche could be viewed as an artist-philosopher, so Beuys could be viewed as a philosopherartist. This deconstructive gesture of thought brings to light the hidden affinity between art and philosophy, which may also be dealing with the same problematic of the human condition, only with different procedures of meaning production.

\section{Beuys' Chair}

The rarest works of art are those that seem as if destiny has allotted them the task of summarizing, in a single material stroke, a dilemma that occupies culture as a whole. This is precisely the origin of their immortality, and such is the artwork of Beuys entitled Fat Chair. The first thing that strikes the eye in this work is the binary structure to which its name testifies: a chair on the one hand, and a lump of fat placed on top of it on the other. These two elements hold a tension, and the question arises as to what precisely is the source of this tension.

To address this, it is necessary to deepen our inquiry into the two elements that comprise the work. First and foremost, we should consider the chair. In some cases, rather than create new objects, art appropriates objects from daily life. In so doing, it alienates them and makes them appear strange, as if they are being seen for the first time. This is precisely what happens with Beuys' chair.

Just as Marcel Duchamp posits a bicycle wheel on a stool, Beuys posits a lump of fat on a chair. In our being in the world, we are constantly surrounded by chairs. Chairs are to be found in the public sphere-in cars, cafes, streets and parks. Chairs are also to be found in the workplace-the manager's chair, the student's chair, the clerk's chair, the patient's chair and so forth. Chairs are also to be found in our homes, usually outnumbering the inhabitants: there is the chair in the kitchen, the chair on the terrace, and so forth. As we go from chair to chair during the day-from the kitchen chair to the car seat to the work chair-we tend to forget what chairs are for in the first place. It is as if Beuys wrests us out of this game of chairs and invites us to ponder the essence of the chair for the first time.

And indeed, following Beuys, a number of questions arise. What are chairs for? Of course, they are for sitting on. But what is sitting for? One needs to sit, sometimes desperately, since it can be hard to stand up for long periods. Sitting should be viewed as an intermediate solution between lying down on a bed, so natural to our bodies, and standing upright, which our bodies can find hard to 
maintain. This intermediate solution enables us to remain engaged in the world, to write and to eat for example, with a significant decrease in the effort it requires.

In this sense, a chair is a human-made object which perhaps defines the human as-such. A chair is a human object, since only humans can sit. Only humans can sit, since only humans can stand. By way of negation, the chair therefore testifies to the uprightness of humans; to the fact that, at some time in the course of their history, they began to stand on their feet. As such, the chair is deeply connected to the ethos of the uprightness of humans, and along with this, to their essential difference from other animals. Animals do not sit-in the human sense of the word-since animals do not stand in the first place.

According to Bataille, this creates a hierarchy of organs: in animals, the head and buttocks are at the same height, while in humans, the head is higher than the buttocks, and is thus considered to be a more valuable organ. Bataille's aim-most apparent in Story of the Eye-is to deconstruct this hierarchy and restore equilibrium in terms of height, and so equality, of the head and the buttocks, as is the case with animals (Bataille 2013). ${ }^{1}$

After this general reflection on the essence of chairs, we now turn our attention to Beuys' chair in particular. The first question that arises is why Beuys chooses this particular chair. The answer is clear: the chair he chooses is the most functional one, aspiring to a zero degree of comfort and verging on asceticism. What is immediately striking is the chair's minimalism, intended to avoid any feature that is not related to function.

In passing, it is worth mentioning similarities with Freud's chair. ${ }^{2}$ In Freud's chair, the framework only supports the body where it is most needed, along the arms and the back; any trace of excessive comfort is absent from the chair, giving rise to a skeleton of a chair. The weird design was intended to support the rather eccentric sitting position in which Freud used to read. The chair generates a distinct uncanny feeling in its beholder. Besides being due to its weird design, this uncanny feeling most likely arises from the resemblance of the backrest feature to the shape of a

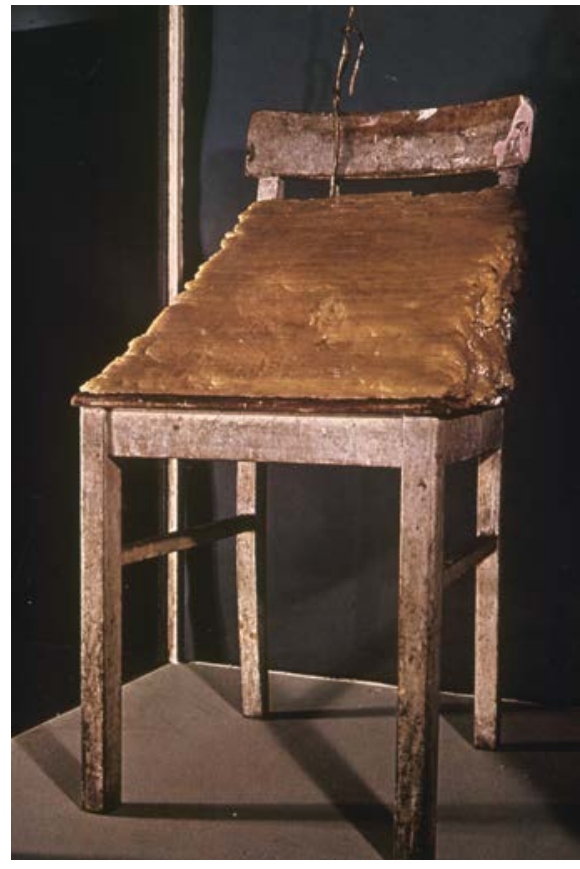

Fig.1: Joseph Beuys, Fat Chair (1964). Fat, wax, barbed wire, wooden chair, $41.6 \times 94.5 \mathrm{~cm}$.

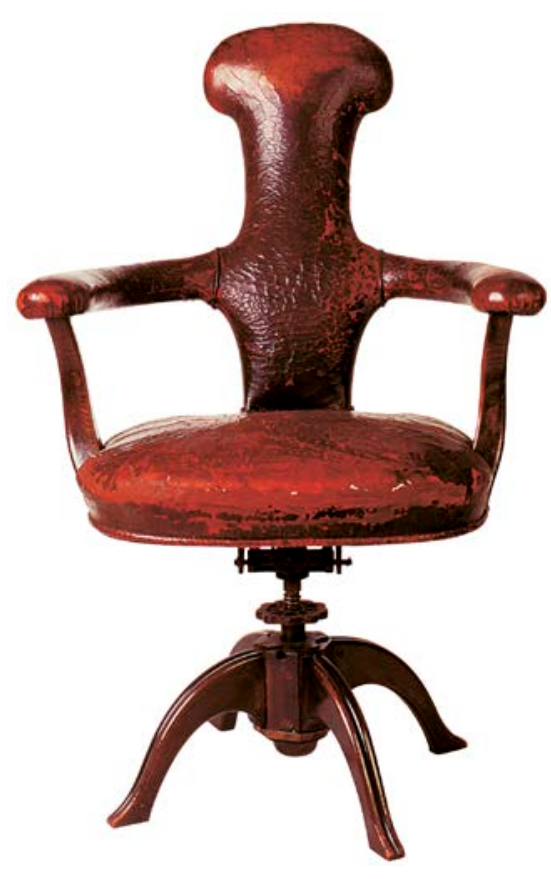

Fig.2: The chair in Freud's work room. Freud Museum, London. 
human figure, bringing to mind the anorectic human figure apparent in Giacometti's sculptures. The uncanny feeling probably stems from the fact that, even when no one is sitting on the chair, it seems as if someone still occupies it—that is, the backrest itself.

In the words of Le Corbusier, the chair-whether Beuys' or Freud's-is thus turned into a "sitting machine," destined to fulfil its function and nothing more. Comfort is therefore sacrificed for the sake of functionality. What is important is that this functionality contributes to the policing of ways of sitting on the chair. This policing minimizes the range of sitting postures and positions available to the body. In fact, it would appear that this policing is precisely what interests Beuys about this chair; that this policing is precisely what justifies his choice; and this choice reveals the violence of the chair. Here we come to what could be seen as a paradox: on the one hand the chair is a product of culture, symbolizing the difference between the human and the animal; while one the other hand, it is a violent object, executing forceful and coercive practices of limitation and regulation on the living body. But is this really a paradox? Perhaps culture is violent in its very nature, no less than nature itself. Beuys' chair therefore invites us to reflect on the relation between violence and culture, and hence on the nature of violence as such.

\section{The Violence of the Other (ha-Rav)}

Indeed, what does culture have to do with violence? The usual answer to this question is that culture is aimed at reducing violence in order to guarantee coexistence. But as we have seen, this product of culture called chair turns out to be a violent machine. How can this be? To answer this, we clearly need to further deepen our inquiry into the essence of violence.

To this aim we must be violent with violence by making a distinction within violence itself. It can be argued that the violence of culture, as manifested in the chair, is not the first violence; that it is in fact preceded by another violence: the violence of the Other. Following Benjamin, the violence of culture-as it is manifested in the chair for example_can be termed secondary violence (Benjamin calls this law-preserving violence). This violence is preceded by another violence, the violence of the Other, that can be termed primal violence (Benjamin calls this law-making violence) (Benjamin 1986, 277-300). In the beginning, then, there was violence.

But what precisely is the nature of this primal violence? Any attempt to define it will miss the mark, since the violent nature of this kind of violence is manifested precisely in its fierce resistance to definition. This resistance is the origin of its violent nature; it is violence itself. Nevertheless, the resistance to definition can provide us with an initial definition by way of negation: primal violence is concerned with resistance to any attempt at definition. Definition is the first step towards identity, and in this sense, primal violence can be viewed as an all-out war on the first principle of philosophy: the principle of identity.

Primal violence can be viewed as an arch-war, a war at the arche ("origin"). This is a state of war of every one against every other; of the one invading the other up to the point where there is no one and no other. This involves the blurring of any border or identity, and hence any definition. This is 
why primal violence can also be termed the violence of difference, when thought in line with Derrida (1982, 1-27), or the violence of the Thing when thought in line with Lacan (1992, 43-57). I myself wish to call it the violence of $h a-R a v^{3}$

The introduction of this Hebrew neologism can be justified in several ways: Firstly, one should always aspire to philosophize in one's own mother tongue in order to retain in the discourse the pre-Oedipal, and hence pre-logical, reverberations of language, i.e., the semiotic, as Kristeva would have it.

Secondly, the Hebrew language in particular, as with the Greek language, can be counted among the primordial philosophical languages, in which the fundamental philosophical terms such as Being ("Havaya" in Hebrew, which stems from the very same root as the unspoken word "Yehova," i.e., "God") were first spelled out. This testifies to an inner connection between philosophy and the Hebrew language.

Thirdly, and perhaps most importantly, this Hebrew neologism achieves what is practically unachievable in other languages, i.e., it captures in a single word both the Thing and its innate violence. How is this so? It just happens, by pure chance (or not?), that this Hebrew word-ha-Ravcarries three distinct yet connected meanings: "manifold" (ribui); "quarrel" or "dispute" (riv); and "sovereignty" (ribonut), from which the word Rabbi is derived and with which the English reader is perhaps better acquainted. These three meanings incessantly contaminate each other: it could therefore be argued that the irreducible manifold of ha-Rav is in constant quarrel and dispute; and that this disputed manifold should be viewed as the first sovereign, since all other sovereignswhether the super ego or the state-as Freud and Benjamin show us, draw their sovereignty from it.

The violence of the Other (Rav) does not necessarily carry a negative sense, being both beyond good and evil, and before there is even any difference between the two. It does not resemble human violence since human violence is mostly engaged with intention, and even pleasure. The Violence of the Other (Rav) is instead violent in the sense that it devours any gesture on behalf of any being, whether object or subject, to constitute an identity of its own. Any gesture of this kind immediately crumbles into the beaten being of the Other (Rav), in which there is only room for manifold, and not for identity; and which devours anything that wishes to differentiate itself as a being from Being or as thing from the Thing. Just as the Other (Rav) is indifferent to the difference between good and evil, so it is indifferent to the difference between object and subject. The violence of the Other (Rav) could therefore be considered as preobjective and presubjective.

From the side of the object, so phenomenology teaches us, the violence of the Other (Rav) is embodied in excess, prior to any determination. Out of this excessive excess, with the help of categorical reductive and formative procedures, the thing called "object" will eventually unfold. From the side of the subject, so psychoanalysis teaches us, it is manifested in the bunch of drives called "Id," and from this bunch of drives, with the help of the procedures of repression and denial, the thing that calls itself "I" will eventually unfold; it "must" unfold, so Freud teaches. 
The concept that is not a concept of ha-Rav, therefore, violates the distinction between object and subject as it resides on both sides of this difference; it is "outside" as well as "inside."

\section{The Violence of the Father}

The discussion of the limitation procedures taking place from the side of the object, as well as from the side of the subject, enables us to trace the initial contours of secondary violence. From the side of the object, it could be termed violence of the category. As is well known, Kant supposes the sensuous giveness (Gegebenheit), that spontaneously comes from outside, to be chaotic, and hence un-understandable. The main thrust of his Copernican revolution resides in his claim that the constitution of the sensuous giveness (or sensual Rav) into a meaningful world occurs with the help of twelve a priori concepts-the categories-whether unity, manifold, cause, substance, and so forth. The apprehension of the sensuous Rav through the categories constitutes it into a distinct object which Kant designates as "phenomenon." In this way, the categorical constitution creates an understandable world that is subject to the laws of science which stem from the structure of reason itself (Kant 2004). But this constitution of a meaningful world is essentially violent since it entails the reduction of ha-Rav. The secondary violence of the category could therefore be thought of as situated in an opposition to the primal violence of ha-Rav.

From the side of the subject, we shall refer to the secondary violence as the violence of the Father. Of course, this does not refer to the biological father of flesh and blood, but rather, the symbolic father in the language of Lacan. According to Lacan's critique of Freud, the pivotal figure of the father should be stripped of its concrete physiological traits and instead be thought in structural terms as a function of signification. Lacan's symbolic father functions first and foremost as an agent of the law, an agent that enforces this law coercively and violently on the newly-born subject, and ushers her/him into the Symbolic Order.

However, before the newly-born subject can turn into a speaking-being (parlêtre) and be assimilated into the Symbolic Order, she/he must go through a process of figuration and identification that is achieved in what Lacan terms "the mirror stage." By going through this mirror stage-in which the reflection of the holistic figure of the body as it appears in the mirror is projected onto the chaotic and formless primal self-the subject acquires an ideal and hence imaginary identity of her/his own (Lacan 1993, 107-142).

Ha-Rav, in its subjective context-that unbridled bunch of drives of the primal self, more of an "It" than an "I"-discovers in front of the mirror the joy of gazing at the whole and harmonious figure of the body. This is the first time, so Lacan's myth of the mirror stage tells us, that ha-Rav in its subjective context encounters identity; that is, something whole, ideal by nature, which is nothing other than the figure of the body. From here on, ha-Rav will undergo an idealization process: in aspiring to identity, it will peel off its instinctual excess and dress itself in the ideal but imaginary figure of the thing called "I." 
The imaginary I will then be ushered into language by its trembling symbolic father, as Isaac led by Abraham to Mount Moriah. This sacrifice of the first-born, violent in itself, is embodied in the Lacanian term the Name of the Father (nom du père). This term connotes, not only the name, but also the law, since the name and the law are linguistically affiliated due to the fact that the origin of the name of the name (nom) is the name of the law in Greek (nomos). So we are dealing here with a double sacrifice: the symbolic father not only enforces on the subject the name in particular and language in general, but also the law (Lacan 2006, 67).

How should this duplicity of the name and the law be understood? By ushering the subject into language, the symbolic father enforces the exchange of the lively thing with its ossifying name. This is a violent exchange involving the murder of the thing by the word, as Lacan puts it (Lacan 1993, 174). The name stands, of course, for the signifiers in their entirety, first and foremost linguistic signifiers. At the same time, the father also enforces the law forbidding incest which, as shown by Kristeva, is the origin of all laws (Kristeva 1982, 90-112). The ban on incest enforces the exchange of the first object of desire (the Mother) with secondary objects, and hence the exchange of enjoinment (jouissance), i.e., sexuality without restriction, with pleasure (plaisir), i.e., sexuality under the restriction of the law. The subject is thus ushered into the unpromised land of the Oedipal universe, that penal colony of the castrated, created by the simultaneous harsh reduction of the thing (signified) to the word (signifier) and enjoinment (sexuality without restriction) to pleasure (sexuality under the law's restriction).

These two-the name and the law-are secretly bound together: the violence of the law that enforces castration is precisely that which generates the signifier, which brings about the exchange of the thing with the name. The name is thus acquired by the sacrifice of the most precious, enjoinment; but at the same time, the name is also a gift as it enables language, and hence culture as a whole.

This bond between the name and the law is most apparent in the act of circumcision. This can perhaps only be properly articulated in Hebrew, due to the rather surprising fact that the Hebrew term for circumcision (Brit Mila) binds together the values of "castration" and "word" by rendering them in the same notion (Mila). In this sense, the term literally says "the pact of circumcision/word." This is, then, the essence of the pact: in being circumcized (Mila), that is, in the inscription of the law on the body, the subject is given the word (Mila), that is, language and culture as a whole. The gift of language is therefore connected to circumcision. ${ }^{4}$ In other words, circumcision subtracts the Thing from the body while giving it the name. The pact of circumcision/word (Brit Mila) ushers the subject into what can be termed the Order of Circumcision/Word (Seder ha-Mila).

The above is further reinforced in Freud's "Totem and Taboo," which tells the story of the birth of humanity (Freud 1950). Freud posits a paradox: the law forbidding murder is itself won by an act of murder. The murder of the primordial father by his sons is precisely that which guarantees the ban on murder. In that, it paves the way for the first social contract. The primordial father has an infinite amount of violence and enjoinment at his disposal, which he exerts mercilessly on the members of his pact: his sons and daughters. The only way to escape his tyranny is to murder him. 
In the horrific act of murdering their father, the sons constitute the law, so guaranteeing that neither of them will possess full ownership over violence and enjoinment, and leaving each of them with only a leftover of it. The murder of the father should be thought of as an unwanted necessity, since it prevents violence of a more horrific kind-the violence of the first father, the biggest assassin of them all.

It is important to differentiate between two categories of fatherhood: the primordial father, who precedes castration and is hence placed outside the Order of Circumcision/Word (Seder ha-Mila); and the secondary father, i.e., the Oedipal Father, who is castrated and hence situated within the Order of Circumcision/Word (Seder ha-Mila). In this sense, the murder of the primordial father belongs to the secondary violence; that is, the violence of the (Oedipal) Father emplaced over against primal violence, that of the primordial father.

This secondary violence-the violence of the (Oedipal) Father-can be recognized as the violence of economy in all its various manifestations. In this sense, it should also be considered as the violence of identity. The violence of the Father is emplaced over and against the violence of the Other (ha-Rav). Between these two kinds of violence, violent strife rages. Despite its injustice and wrong doing, the violence of the Father should be considered a necessary one, defending us from a more horrific kind of violence. The choice to be made is not between violence and nonviolence, but rather between two kinds of violence, the second being the lesser one.

\section{Beuys' Fat}

We can now say that the murder of the Thing by the category in Kantian terms, or by the word in Lacanian terms, and the murder of the (primordial) father by his sons in Freudian terms, is also present in the chair. If the category and the word murder the Thing, so the chair murders the body. In its form, the chair embodies the presence of law in space; as such, it serves as the delegate of the violence of the Father turned against the living body. The chair, as we have seen above, violently denies the body a whole array of postures-such as lounging, stretching, and so on-in which the body feels comfortable and at ease. It tears the body away from the comfort of lounging, and it deports it to the exile of sitting.

If the subject of the violence of the chair in general is the living body, the subject of the violence of Beuys' chair is fat. When Beuys loads the lump of fat onto the chair, he confronts it with it's entirely other. The chair is an object of culture, while fat is an object of nature. The chair possesses a stiff and ascetic form. Fat, on the other hand, is formless and excessive, and it assumes the form of the vessel in which it is contained. The chair is structured, while fat is a-structural.

Fat should be viewed as surplus energy, extracted from the economy of metabolism and accumulated in reserve for future consumption. In this sense, not only does fat slip from structure, it also slips from economy in general, and in particular from the economy of life preservation. This is why_as already acknowledged by Mark Taylor (Taylor 2012, 16-19)-it is considered to be an abject material, repressed and extracted from the economy of the body as well as from the 
economy of cultural representations. What is fat, then, if not a materialistic embodiment of that violent Other (ha-Rav), alien to structure and economy. Against this abject, excessive, and violent Other (ha-Rav), the violence of the chair comes forth and enforces form on it.

As is well known, fat also carries a personal significance for Beuys, stemming from the trauma he suffered during World War Two when his Stuka dive bomber was shot down over the Crimea Peninsula. Beuys survived the crash and was taken care of by a local Tatarian tribe who applied animal fat to his body and wrapped it with felt. This healing procedure preserved his body heat and prevented him from freezing to death. After the war, Beuys would turn this story-which was never properly verified-into his formative myth as an artist, echoing the myth of Christ: only he who has dwelt near death; only he who has lost his life and then been reborn, can create art. The creation of meaning must undergo the utter loss of meaning.

Moreover, only he who has gone through such an experience understands that life is constantly under threat and subject to extinction at any moment. This is why Beuys lives in a constant state of emergency: at any moment he is ready for catastrophe to befall him, and because of this, he is equipped with appropriate means of survival, such as his trademark, the multipocketed vest. The experience he has undergone also accords him the privileged status of the shaman, which he declares by wearing his hat, also his trademark. In this way, art and life are intermixed: art employs living materials, and the artist becomes a walking piece of art.

This myth gives fat a personal significance on top of those already mentioned. As a material that saved his life, fat-along with felt, copper, honey, and gold-turns into a life conducting material in Beuys' sculptural vocabulary, a material that is able to preserve life energy and conduct it to wherever it is most needed.

And indeed, it is most needed: it is not only Beuys that is in a state of emergency, but also the society in which he lives. This holds true mainly for the 1960s and 70s in which Beuys was active. The mission Beuys undertakes in these years, performed in a sense of unprecedented emergency, is that of primarily healing post-war Germany, in which death had become a thriving industry, by reconnecting it to the life energies of ha-Rav through life preserving materials, primarily fat.

This holds true, not only for Germany, but also for society as a whole, especially American society as the main force driving capitalism. As his work I Like America and America Likes Me indicates, Beuys is also concerned with America. To heal America he recruits the coyote, the wild wolf that used to roam its prairies. For him, the coyote is just another embodiment of the vital energies of ha-Rav, which, like fat, is employed by him to heal America that has detached itself almost completely from Nature by an ever-growing capitalist entrepreneurism. This holds true, not only in the $20^{\text {th }}$ century, but also in the $21^{\text {st }}$ century. In early capitalism, the merchandise that emerged from the production lines exchanged natural matter. In the late capitalism of our age, the simulacratic representation seen on our TVs, computers, and iPhones replaces merchandise itself. This is a state of emergency since this age of accelerated capitalism in America, and worldwide, alienates us from being before the signifier. 
After explicating the significance of the chair and the fat, we can now make sense of Beuys' work as a whole. Beuys brilliantly articulates the aporetic tension between the violence of the Father and the violence of the Other (ha-Rav). As we have seen, the chair stands for the violence of the Father, while the fat stands for the violence of the Other (ha-Rav).

Between these two, a pact is made-the pact of the chair and the fat-which could be viewed as a material manifestation of the pact of the Order of Circumcision/Word (Seder ha-Mila) mentioned earlier. As such, Beuys' work serves as a materialistic embodiment of the fissure between the violence of the Father and the violence of the Other (ha-Rav), and in this way, it articulates the aporia occupying culture as a whole.

But precisely in what way is this aporia articulated in Beuys' work? To answer this, we must come back to the fat. As already mentioned, fat should be considered as a reservoir of excessive energy extracted from the life preservation economy of the living body. As such, it should be considered as belonging to the violence of the Other (ha-Rav). But what has eluded our attention so far is that the real living fat-that which embodies body tissue-is not the fat appearing in Beuys' work.

This is for three reasons: firstly, Beuys' fat is industrialized, having undergone complex production procedures. This is precisely what motivated Beuys' critics, who found it hard to notice the difference between his use of fat and the way it is used in the food industry. The amount of fat used in the discussed work is nothing compared to that used in another work of Beuys, dated 1977, and taking place in the city of Münster. In this work, Beuys filled up an entire underground pedestrian passage with animal fat. This was later cast into gigantic lumps and displayed under the title "Tallow." This monstrous amount of fat-the monster of Münster-raises the question of human's carnivorous violence against animals. It points to the fact that the Treblinka concentration camp is a mundane reality and part of the daily life of animals. This monstrous amount of fat also raises other monstrosities from the dead, such as the fat of the exterminated Jews nourishing the soil of Auschwitz.

Secondly, the fat appearing in the work is not shown in its crude, natural state, but is rather formalized into a geometrical shape of a triangular prism. It is true that this shape escapes strict precision, given the fact that its flanks still reveal the somewhat rough un-linear texture of the fat of which it is made. But nevertheless, it is still a form, perhaps the zero-degree of form.

Thirdly, the fat is torn out of its environment and placed on a chair, which serves as the stage of its appearance. Not only the chair itself serves as a stage of appearance, but also the museum in which the chair is situated, and hence, the entire cultural array which enables the visibility of art.

The living fat has therefore undergone reduction through three distinct but related procedures: its industrialization, its formalization into a triangle, and its appearance on the stage of art. Having undergone these three reductions, it could be said-contrary to Taylor's approach which identifies Beuys' fat as being real fat (Taytlor 2012,16) -that, in line with Derrida's spectrology as formulated 
in his later writings (Derrida 1994, 1-60), Beuys' fat is therefore not real fat, but rather a specter of fat.

This, then, is the aporia of fat: its significance as an excessive, violent, abject material, pertaining to the violence of the Other (ha-Rav), must be lost in advance in order for it to appear in art. Fat "itself," as it is to be found in animal flesh prior to its industrial processing for example, is practically meaningless. Fat only comes to acquire its meaning when, having been utterly lost in its formation processes, the cultural process enables its appearance in art. The appearance of fat in art is therefore conditioned by the loss of its being.

We are dealing here with an argument of a much greater scale: the noneconomical violence of the Other (ha-Rav) can only appear through the economy of the violence of the Father. It should be stressed that-drawing mainly on Levinas and Derrida-the notion of economy is employed here in its broad sense, as pertaining to any procedure of measuring, numbering, reckoning, calculating, and so forth, and hence of limitation and reduction, ${ }^{5}$ whether it be executed in economy in the strict sense or in the fields of culture and society, as well as in those of epistemology and ontology.

Thus the precultural and presymbolic excess and violence only acquire meaning from within culture, that is, within the economy. But in order to appear in culture, it must lose its being. This aporia was probably articulated for the first time in the later stages of Heidegger's thought: the primordial meaning of Being can only appear through the misleading interpretations of Being which constitute the history of metaphysics. This aporia is further articulated by Derrida in the concept that is not a concept of différance.

This is precisely the place to host the notion of hospitality to which this path of thinking has led us so far. The notion of hospitality goes hand in hand with that of the aporia since the aporetic manifestation of one element within the other, justice within law for example in Derrida's case (Derrida 1992) or the violence of the Other (i.e., the fat) within the violence of the Father (i.e., the chair) in Beuys' case, is none other than the hospitality of the entirely Other within any given economy, be it the economy of law in Derrida's case, or the economy of culture in Beuys' case. These economies should be viewed as different names for what is termed here the violence of the Father.

This claim enables us to shift the discourse of hospitality originating in Levinas from the social sphere to the aesthetic sphere. Levinas situates hospitality within the other human's face. The hospitality at stake is that of the other confronting the self face-to-face. The hospitable self must relinquish his desire to kill the other, and in so doing make way for the other to traumatically breach the economy of his solipsistic world. For hospitality in this sense Levinas reserves the term "Ethics," which is identified with Justice, and so resists translation into a system of laws, that is, what can be termed "morality" (Levinas 1979, 194-211). The entire force of Levinas' argument rests on his insistence on regarding the social sphere-where the encounter with the other takes placeas the sole sphere in which the event of hospitality takes place. In doing so, he denies art the possibility of acting as a sphere of hospitality (Levinas 1987). Contrary to Levinas, what is stated here insists on identifying art as a sphere of hospitality of the entirely Other, who is not to be identified 
with a benevolent God, as in Levinas' case, but rather, with the violent Rav. This approach to art as a sphere of hospitality of the entirely Other could therefore be termed "Aesth-ethics." That is, art as the hospitable event of the coming of the Other.

As we have seen, Beuys' chair is a hospitable place, and as such, it can serve as a paradigm for Aesth-ethics, that is, of the event of hospitality of art. What is hosted in Beuys' chair is precisely haRav, this excessive violence and violent excess in the form of a lump of fat. Just as in the case of the prophet Elijah-hosted on an empty chair during the Passover feast-so ha-Rav does not appear on Beuys' chair in itself, in its flesh and blood so to speak, but only as a specter. Ha-Rav does not appear in itself since Beuys' fat is an industrialized fat, a cultivated fat, which has been through a long process of production before appearing on the stage of art. The real fat-if such a thing exists at all-has been lost in the processes of its production and appearance, that is, in the violence the Father. In this sense, the hospitality of art is aporetic. The thing that is not a thing called ha-Rav appears and does not appear in art; is present and not-present in it. It presents itself as a ghostly guest while departing, leaving behind a trail of that spectral scent preserved for festive events only.

According to Derrida, the notion of aporia is in fact disseminated into an infinity of aporias since it is of its nature never to be one (Derrida 1992, 3-67). To formulate a phrase like this means to do wrong to the aporia since the notion of aporia constantly undermines anything that declares itself to possess a "nature," or an "essence," of its own, anything which is pure and self-identical. This failure resides at the core of the traditional philosophical procedure of knowledge production which Derrida himself wishes to deconstruct. Precisely herein resides the power of Beuys' art in particular and art in general: its ability to make manifest, in a single material stroke, the aporetic tension that constantly escapes traditional philosophical conceptualization.

It could further be argued that the aporia of the hospitable work of art is also the aporia of the hospitable work of art interpretation. As the work of art itself, it labors to capture the uncapturable. With its network of signifiers, the work of interpretation labors to capture that elusive thing-the Saying of art-which constantly resists formulation and evades discourse. In attempting to say that which is fated to remain unsaid-which is probably left unsaid in this article as well-the work of interpretation finds itself captured within an infinite hermeneutics.

\section{From Fat to Ice: The Israeli Condition}

Contrary to the banal conviction, adopted almost blindly by so many without further questioning, that philosophy deals with the most abstract and universal, I wish to uphold the contrary view according to which philosophy grows out of daily life and the concrete place in which this life is enfolded. This view has its roots already in Greek philosophy, as is attested by so many Greek philosophical terms originating in daily life. This is the case, for example, with the Greek word ousia, which, prior to its appropriation by philosophy, simply meant "household." This is also the case with the Greek word idea, which in its un-philosophical use simply means "the visual aspect of things." 
In this regard, it can be further argued that one cannot philosophize without taking into account one's own personal circumstances stemming from one's own bedrock of existence. As such, I would like to proceed with an analysis of a local work of art, made under the harsh light of the Israeli sun. As we shall see, this artwork bears a striking resemblance to Beuys' Fat Chair. It is further argued that this artwork-just as Beuys'-also bears heavy political implications ensuing from the Israeli condition, which cannot be ignored.

The same aporetic hospitality residing in Beuys' Fat Chair could also be found in David Brailovsky's artwork entitled The Ice Keeper. While Beuys' work is comprised of a chair holding a lump of fat, Brailovsky's work is comprised of a pair of hands holding a lump of ice. As such, the lump of fat is replaced with a lump of ice, and the holding capacity is transferred from the chair to the hands. But despite this exchange and transference, the tension between a human element (chair/hand) placed below, and a nonhuman element (fat/ice) placed above, still exists.

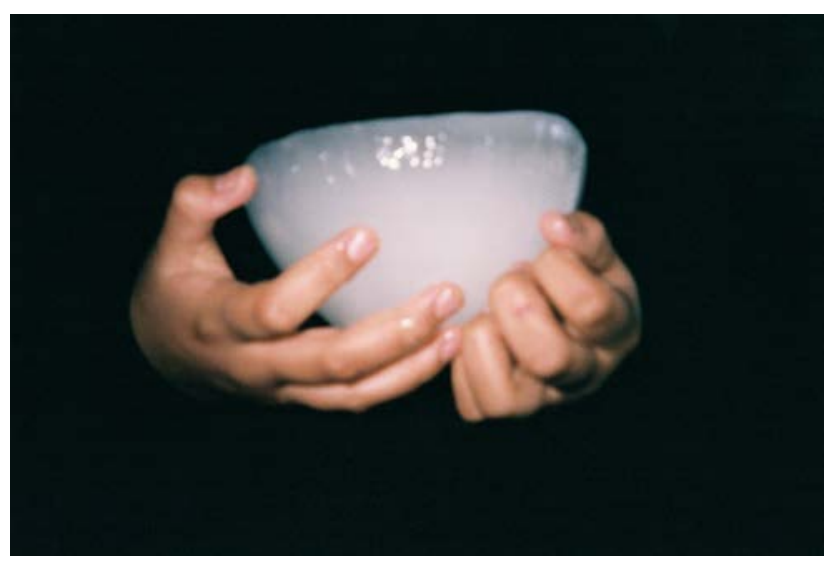

Fig. 3: David Brailovsky, A still picture from the video work The Ice Keeper (2010), 24x37cm. The artist's collection.

Although the chair and the hand seem at first to be essentially different, even on the verge of opposition-since the chair is adjunct to the body while the hand belongs to the body-their juxtaposition reveals a purpose common to them both, that of holding: the chair holds the body while the hand holds the object. The hand, so to speak, is the chair of the body.

The chair and the hand also resemble each other in the sense that both host the humanity of humans. As mentioned above, the object called chair attests to the ethos of the uprightness of humans, distinguishing them from other animals. Following Heidegger, it could be said that the hand also attests to the humanity of the human: as part of his effort to embody thought, Heidegger locates the humanity of the human in the hands rather than in the mind since the hand is envisaged as a phenomenological appearing locus of Being. Since the humanity of humans is determined according to their relation to Being, and since the hand serves as an appearing locus of Being, the humanity of humans reside in their hands (Heidegger 1982, 117-124). This argument can be further reinforced from a linguistic perspective: in German, the word articulating the holding capacity of the mind (Begriff) is derived from the verb articulating the holding capacity of the hand (greifen). In English, these holding capacities of the mind and the hand are articulated by the same word-grasp-which can be used either literally, in the sense of grasping by the hand, or metaphorically, in the sense of grasping by the mind.

The chair and the hand are also similar in the sense that both are given the task of grasping the ungraspable: fat and ice. Both materials are flexible, constantly shifting between liquid and solid. 
This is why they both possess a zero degree of form which could evaporate in an instant. This is also the reason for their smoothness as well as their violence. As a reservoir of surplus energy, fat manifests the violence of devouring. Ice is the manifestation of the violence of the elementalwater in this case-inflicted on the hand as it tries to take hold of it. The holding of ice can only subsist for a few seconds due both to its smooth elusiveness and the frostbite it inflicts on the skin. In this way, just like fat, ice can be viewed as material embodiment of the violence of ha-Rav.

Similarly, just like the fat in Beuys' work, the ice in Brailovsky's work does not appear in its crude materiality. From the elemental ice of the mountain peaks in Antarctica and Himalaya, only a truncated leftover remains, shaped in the form of a plastic funnel that is filled up with tap water and placed in the freezer on the evening prior to the shooting of the picture. Like the fat, ice was torn out of its natural environment and placed in the hands that serve as the stage of its appearance. This is the aporia of ice: its violent nature must be lost in advance in order for it to appear in art. It only acquires its meaning as primal violence when its being is lost in its appearance in art. Art, then, serves as the "ice keeper," in which ice "itself" only appears as a trace and a specter, as erased appearance, and as domesticated violence.

The political context of Brailovsky's ice should not be ignored: the picture discussed is only part of a larger video work which bears the same title. ${ }^{6}$ The hands holding the ice and disappearing in the background darkness belong to a Palestinian teenager from Jaffa. The depicted ice does not originate in Antarctica or Himalaya, but rather in an ice cart that used to roam the streets of Jaffa. This ice cart-around which the video's narrative is woven-serves as a reminder of the beauty of Jaffa before its occupation during the Israeli War of Independence, that is, before it was appropriated by Zionism.

Spectral remains of this bygone world can be found to this day along the Tel Aviv beach, mainly near the Hasan Beck mosque. Most of those who visit this place are unaware of the fact that the mosque is the sole building that remains of the Manshie neighborhood, which served as the border separating Jaffa from Tel Aviv, and of which only tile fragments glittering in the beach sands remain. Art, therefore, is the keeper, not only of ice, but also of the politically repressed, of that lost world of the city of Jaffa before it was violently erased by the Zionist occupation.

As suggested above, this is the case, not only of Brailovsky's ice, but also of Beuys' fat. Indeed, Beuys' fat serves as a spectral reminder of that monstrous nature which is termed here ha-Rav. However, by the same token, it might just as well serve as a spectral reminder for the monstrosities of Auschwitz, that is, for the Jews' body fat that was deposited in huge pits dug out in the fertile fields surrounding the death camp.

In conclusion, as we saw, the ice and the fat are both abject materials; are both aporetic specters of ha-Rav. At the same time, they both serve as a trace of a violence directed against the other, be it the Jews in Beuys' case or the Palestinians in Brailovsky's case. The fat and the ice-as spectral bearers of that violence against the other-find themselves opposed one against the other in an antithetical fashion. By doing so, they form a kind of an unresolved deadlock-a deadlock of violence-within which the Israeli condition resides. 
${ }^{1}$ Towards the end of Story of the Eye, the heroine pulls out one of the priest's eyeballs, and shoves it into her vagina. In so doing, she wishes to equalize the value of the organ of sight (symbolizing reason), with that of the sex organ (symbolizing corporeality).

${ }^{2}$ This is to be found in the Freud Museum in London. It was especially designed for Freud as a birthday gift by the architect Felix Augenfeld in 1930 at the request of Freud's daughter, Mathilda.

3 The syllable "ha" serves as the Hebrew prefix for articulation.

${ }^{4}$ It is true that the phenomenon of circumcision is discussed in the psychoanalytic literature mainly from the perspective of the male sex. This can attest to a theoretical lacuna to be found in Freud, who devotes his argumentative thrust mainly to male sexuality while neglecting female sexuality. However, in an attempt to complement this lacuna, it could be argued that female circumcision practices do exist, and can be found to this day in native tribes in Africa, as well as in the Middle-east and Asia. With migration, however, it is now spreading to Western countries, and there are instances of it being carried out in Europe and America, even though it is illegal there.

5 The term "economy" is derived from the juxtaposition of two Greek words: oikos, which means "home", "house", and "household", and nomos, meaning "law." The literal translation of "economy" is thus "house laws."

6 https://www.youtube.com/watch?v=u4TbYf7U248

\section{Works Cited}

Bataille, George. 2013. Story of the Eye. Translated by Joachim Neugroschel. London: Penguin.

Benjamin, Walter. 1986. "Critique of Violence." Translated by Edmund Jephcott. In Reflections: Essays, Aphorisms, Autobiographical Writings, edited by Peter Demetz, 277-300. New York: Schocken.

Derrida, Jacques. 1982. "Différance." Translated by Alan Bass. In Margins of Philosophy, 1-27. Chicago: Chicago University Press.

1992. "Force of Law: The 'Mystical Foundation of Authority'." In Deconstruction and the Possibility of Justice, edited by Drucilla Cornell, Michel Rosenfeld and David G. Carlson, 3-67. New York and London: Routledge.

_-_- 1994. Specters of Marx: The State of Debt, the Work of Mourning and the New International. Translated by Peggy Kamuf. New York and London: Routledge.

Freud, Sigmund. 1950. Totem and Taboo. Translated by James Strachey. New York: W. W. Norton.

Heidegger, Martin. (1942/1943) 1982. Parmenides, Gesamtausgabe, 54. Frankfurt a. M: V. Klostermann.

Kant, Immanuel (1783) 2004. Prolegomena to Any Future Metaphysics: That Will be Able to Come Forward as Science. Translated by Gary Hatfield. New York: Cambridge University Press. https://doi.org/10.1017/CBO9780511808517

Kristeva, Julia. 1982. Powers of Horror: An Essay on Abjection. Translated by Leon S. Roudiez. New York: Columbia University Press.

Lacan, Jacques. 1992. The Seminar of Jacques Lacan: The Ethics of Psychoanalysis, 1959-1960, Book VII, edited by Jacques-Alain Miller. Translated by Dennis Porter. London: Routledge.

___. 1993. The Seminar of Jacques Lacan: Freud's Papers on Technique, 1953-1954, Book I, edited by Jacques-Alain Miller. Translated by John Forrester. New York and London: W. W. Norton.

. 2006. Ecrits: The First Complete Edition in English. Translated by Bruce Fink, Héloịse Fink and Russell Grigg. New York: W.W. Norton. 
Lauf, Cornelia. 1992. Joseph Beuys: The Pedagogue as Persona. Ph D diss., Columbia University.

Levinas, Emmanuel. 1979. Totality and Infinity: An Essay on Exteriority. Translated by Alphonso Lingis. The Hague, Boston, London: Martinus Nijhoff. https://doi.org/10.1007/978-94-009-9342-6

1987. "Reality and its Shadow." Translated by Alphonso Lingis. In Collected philosophical papers, 1-15. Dordrecht, Boston, Lancaster: Martinus Nijhoff. https://doi.org/10.1007/978-94-009-4364-3_1

Taylor, Mark C. 2012. Refiguring the Spiritual: Beuys, Barney, Turrell, Goldsworthy. New York: Columbia University Press. https://doi.org/10.7312/tayl15766

Tisdall, Caroline. 1998. Joseph Beuys: We Go This Way. London: Violette Editions.

\section{Biography}

Dr. Dror Pimentel teaches at the Bezalel Academy of Art \& Design Jerusalem, both in the History \& Theory Dept. and in the M.A. Program for Policy and Theory of Arts. Among his areas of interest are phenomenology, semiotics and aesthetics. Among his books: The Dream of Purity: Heidegger with Derrida (Magnes Press, 2009 [Hebrew]); Aesthetics (Bialik Institute, 2014 [Hebrew]); Being Written: Heidegger and Derrida (Palgrave NY [forthcoming]).

(c) 2017 Dror Pimentel

cc) (1) Except where otherwise noted, this work is licensed under a Creative Commons Attribution-

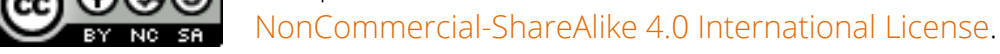

